\title{
EJSBS
}

The European Journal of Social \&

Behavioural Science

ISSN: 2301-2218 (ONUNE)
OPEN ACCESS

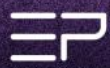

The European Journal of Social and Behavioural Sciences

EJSBS Volume XXX, Issue I (eISSN: 2301-2218)

\section{ENFORCED ISOLATION: HOW DOES IT AFFECT THE PSYCHOSOCIAL AND PHYSICAL DEVELOPMENT OF CHILDREN?}

\author{
Sevim Y. Asvaroğlu ${ }^{\mathrm{a} *}$, Fezile Olkanl $^{\mathrm{a}}$ \\ ${ }^{a}$ International Cognitive Behavioural Therapies Society, Trikomo, Cyprus
}

\begin{abstract}
This paper discusses the impact of enforced isolation brought on by the Covid19 restrictions on the psychosocial development and physical well-being of children through a review of relevant literature as the research method. The analysis of the reviewed literature has identified that the impact of enforced isolation include mental health issues such as stress, depression and anxiety as well as physical concerns such as obesity which can have long-lasting effects into adulthood. Severe outcomes extending into adulthood include substance abuse, self-harm, aggressive behaviours and suicidal ideation. The study also offers some solutions on ways to mitigate the effects of enforced isolation on the psychosocial development of children. Maintaining children's physical well-being during the lockdown are also offered as part of the solutions.
\end{abstract}

Keywords: Children's psychosocial development, children's physical health, children's mental health, effects of enforced isolation, Covid19's impact on children

(C) 2021 Published by European Publisher. www.europeanpublisher.com

${ }^{*}$ Corresponding author.

E-mail address: sevimas@live.com

doi: $10.15405 /$ ejsbs.286

This work is licensed under a Creative Commons Attribution-NonCommercial-NoDerivatives 4.0 International License. 
https://doi.org/10.15405/ejsbs.286

eISSN: 2301-2218 / Corresponding Author: Sevim Y. Asvaroğlu

Selection \& Peer-review under responsibility of the Editors

\section{Introduction}

Children are the world's most valuable resource and its best hope for the future.

John F. Kennedy

The Covid-19 lockdown implemented by many governments has affected all sectors of human endeavour from business to healthcare to education. People's lives have been disrupted to an extent never before experienced in human history. Home is now the center of everyone's existence with work and schooling all being done from home. While it is good that there are alternatives to work and education via online platforms, one cannot dismiss the drawbacks that come with being cooped up 24/7 at home, especially on children. Children's psychological, social and emotional development is of utmost importance as they are young and in a vulnerable stage of their life. Studies that have reviewed literature extensively on this topic like that of Ghosh et al. (2020) have emphatically stated that despite being physically resistant to the Covid19 virus, they are nevertheless "hit the hardest by the psychosocial impact of this pandemic. Being quarantined in homes and institutions may impose greater psychological burden than the physical sufferings caused by the virus" (p. 226). Another literature review study by Loades et al. (2020) concur that;

Social distancing and school closures are likely to result in increased loneliness in children and adolescents whose usual social contacts are curtailed by the disease containment measures. Loneliness is the painful emotional experience of a discrepancy between actual and desired social contact. Although social isolation is not necessarily synonymous with loneliness, early indications in the Covid-19 context indicate that more than one-third of adolescents report high levels of loneliness, and almost half of 18- to 24-year-olds are lonely during lockdown” (p. 1218).

Thus, it has been established that enforced isolation does have a detrimental effect on the psychosocial development of children and young adults by affecting their mental wellbeing.

Studies like that of Zhang et al. (2020) have also highlighted that the impact of isolation on children mainly affects their brain development thereby impinging on their ability to interact socially with their environment. Socially isolated children have a high risk of mental health problems, especially when they have moved to the stage of adulthood. The lack of active social relationships eventually affects children negatively based on stunted brain development. However, it has also been found that social isolation affects some children more than it does others because some children are more susceptible than others in their ability to regulate the 
https://doi.org/10.15405/ejsbs.286

eISSN: 2301-2218 / Corresponding Author: Sevim Y. Asvaroğlu

Selection \& Peer-review under responsibility of the Editors

impact as they are able to utilise social support patterns that deflect the risks of social isolation on themselves.

Psychosocial development in children refers broadly to the combination of psychology and social aspects in various stages of human life affected by environmental factors. The leading proponent of psychosocial development is Erik Erikson, a psychologist and psychoanalyst who introduced his theory in the 1950s. He posited that human development can be traced to "eight sequential stages of individual human development influenced by biological, psychological, and social factors throughout the lifespan" which was founded on "Freud's theory of psychosexual development by drawing parallels in childhood stages while expanding it to include the influence of social dynamics as well as the extension of psychosocial development into adulthood" (Orenstein \& Lewis, 2020, para. 1). This maps children's social, physical and psychological developmental milestones according to their interaction with and effects of milieu they are in.

Isolation among children affects their psychosocial development because of limiting factors such as the removal of school and being in environments that lack stimulation for communication and interaction. Based on the findings of the research by Zhang et al. (2020), children who were moderately and highly isolated revealed increased signs of anxiety, conduct problems, and depression especially at age 12 . However, the implementation of emotional and behavioural regulatory systems among children was found to assist in reducing the damaging effects of isolation among children by developing their emotional strength to interact effectively with the environment.

\section{Purpose of the Study}

Many governments have imposed a total to partial lockdown in order to control the spread of the Covid-19 virus. The effects of this enforced isolation on people have been the focus of much investigation. Of particular interest is the most vulnerable group that is children, and how this lockdown is affecting them. Of primary concern is their psychosocial development and their physical well-being as these can be considered the bedrock of human development. This study aims to enrich the corpus of knowledge in this area by infusing the current knowledge with more insights by bringing together different perspectives and commenting on these in order to give them a fresh outlook. Basically, this paper will study what various researches have found on the effects of enforced isolation on the psychosocial and physical development of children, then discuss these findings from our perspective strengthened by our own review analysis in order to make appropriate and relevant 
https://doi.org/10.15405/ejsbs.286

eISSN: 2301-2218 / Corresponding Author: Sevim Y. Asvaroğlu

Selection \& Peer-review under responsibility of the Editors

conclusions. Another purpose of this paper is to offer some solutions to alleviate the worst of these effects for the children and their caregivers.

\section{Research Question}

The following research questions arose from the reading of the literature and the authors' concerns about this particularly vulnerable group during the lockdown.

3.1 What are the effects of enforced isolation on the physical well-being of children?

3.2 What are the effects of enforced isolation on the psychosocial development of children?

3.3 What are some solutions that can help alleviate the effects of enforced isolation on the physical and psychosocial well-being of children?

\section{Research Methodology}

The research methodology utilised was a content analysis of data from a literature review relevant to the topic under investigation which is the impact of enforced isolation on the psychosocial development and physical well-being of children. The literature review as a research method was chosen for this study as it is an efficient method that synthesises strands of previous research done in this area to provide an extensive view of the topic under study. Using the research questions as a guide, the materials selected were analysed thoroughly to capture all the relevant data. To ensure credibility, only journal articles, book chapters and webpage materials of credible organisations dealing with the research topic were selected from databases that contained academic works like google scholar, pubmed and researchgate.

\section{Findings and Discussion}

Children in enforced isolation for extended periods of time is not a new story. In certain circumstances, children are left alone in the home by parents who need to work. Children in institutions such as hospitals may also be considered to be in enforced isolation. While the circumstances may differ in terms of the duration and nature of being isolated, in terms of the Covid19 lockdown, the effects can be assumed to be similar with variances in the degree of impact.

Based on literature on the effects of isolation in general, enforced isolation affects children mentally which later affects their psychosocial development (Frankenberg \& Orfield, 2007). Research has established that the effects of isolation of children contributed to the 
https://doi.org/10.15405/ejsbs.286

eISSN: 2301-2218 / Corresponding Author: Sevim Y. Asvaroğlu

Selection \& Peer-review under responsibility of the Editors

disruption of children's brain development by inhibiting the production and subsequent function of a protein in the brain that is crucial for the development of the nervous system. The affected brain cells and nervous system in turn impede psychosocial development (Partridge, 2010). Studies done on the impacts of enforced isolation among children have revealed that enforced isolation depresses children which affects their overall social wellbeing. Children have been found to experience severe to mild depression and anxiety during periods of enforced isolation. If the enforced isolation continues unabated, the severity of depression can affect their mental health to such a point that they become barely functional. The end result based on the literature becomes dependence on drugs and/or aggressiveness which would continue to impact their mental health into adulthood. Therefore, the literature affirms that enforced isolation impacts children's psychosocial development through mental weakness affecting normal functions of individuals (Zhang et al., 2020).

Enforced isolation for long periods of time requires meaningful understanding and deliberation of mental health concerns such as depression, anxiety that subsequently lead to psychosocial development problems manifested in their behaviors and character (Robison et al., 2009). The effects of such enforced isolation can be extrapolated to the circumstances surrounding the Covid19 lockdown where children are also being isolated "forcibly" by the fear of infection and to control the transmission of the disease. Whatever the circumstances, of the isolation, the effects are similar in that they are being deprived of the mental and psychosocial stimulation that is integral for their overall development. When even adults are reacting badly to the idea of quarantine and social distancing, one can just imagine how much more mentally traumatic it must be for children, especially the younger children who lack the maturity to grasp the gravity of such concepts as lockdown. Furthermore, while adults can occupy their time with work-related activities, children, deprived of their normal school/playschool routine, have absolutely nothing to occupy them except watching television and playing games reducing their existence to one of dreary boredom of having to engage in repetitive, socially and mentally unstimulating activities. This would result in "ennui, frustration, insufficient information, and lack of in-person contact with peers and teachers, lack of personal space at house, and growing financial burden on parents" (Ghosh et al., 2020, p. 228). Added to this would be the terror of domestic abuse and violence as distraught parents lose their source of income due to the Covid19 economic fallout and take out their frustrations on the defenceless children. "Both direct and passive exposure of the children to abuse, psychological aggression and/or physical punishment by caregivers at a very early age leave permanent wounds in the form of impaired development of brain and psyche, higher rates of psychosomatic and neuro-psychiatric disorders, multiple substance abuse and suicidal 
https://doi.org/10.15405/ejsbs.286

eISSN: 2301-2218 / Corresponding Author: Sevim Y. Asvaroğlu

Selection \& Peer-review under responsibility of the Editors

thoughts" (Ghosh et al., 2020, p. 229). It is no wonder then that the analysis of the literature review specially dedicated to the effects of the Covid19 lockdown on children has revealed without a doubt that enforced isolation will have a detrimental effect on children's psychosocial development and physical well-being.

A vital site for the psychosocial development and physical well-being of children is the school environment and the impact of the removal of this essential site is succinctly elaborated by Ghosh et al. (2020). According to them:

For children, school is not only an educational hub, but also a home outside the home with plentiful free space. Schools offer window of freedom, scope of interaction with fellows and seniors, psychological solace besides providing pedagogy and scholastics. Schools play an edifying role in promoting importance of personal hygiene, physical activity, healthy food, and body habits. Even a short-term shutdown of educational institutions and home captivity for children is indeed troublesome and anticipated to have detrimental effects on children's physical and mental health and shatter the sense of normalcy that schools used to provide. (p. 228)

They go on to add that "childhood obesity and reduced cardio-respiratory fitness will be the end result of this long-term physical inactivity, irregular sleep patterns, unfavourable diet plans, sedentary life style, longer smart-phone/television screen time that are being practiced during lockdown and school-closure" (p. 228). In other words, children are experiencing a 'double whammy' in terms of removal of stimulating environments for their development. Not only are they reduced to being little 'zombies' at home because they to be quiet as their parents are now working from home, they also are deprived of school and friends and play. Their normal routine for eating, playing, interacting, and learning are all disrupted and discarded in favor of mindless, passive activities. It has already been established that children thrive on an active diet of interaction and communication with family, peers, teachers and significant others. According to Erik Erikson's Stages of Psychosocial Development (Cherry, 2020), after the age of six or so, peers, teachers and significant others start to replace family as touchstones of communication and interactional stimulus. For growing children, these are the 'vitamins and minerals' of a proper psychosocial diet. Deprivation of these essential vitamins and minerals especially over an extended duration will result in malnourished psychosocial development manifested by children demonstrating symptoms of anxiety, behaviour change such as unwarranted aggression or withdrawal, heightened irritability and high levels of depression. Studies have shown that children in isolation suffered mainly from emotional and behavioural problems making it difficult for them to communicate effectively with others in their environment. Children learn proper communication and social 
https://doi.org/10.15405/ejsbs.286

eISSN: 2301-2218 / Corresponding Author: Sevim Y. Asvaroğlu

Selection \& Peer-review under responsibility of the Editors

behaviours by mimicking others. Isolation, by removing this integral resource of modelling, would effectively render a child a psychosocial misfit. Bayar and Zontur (2020) concur by adding that children in such situations experience "a stimulus deficit" heightening their vulnerability. The authors added that "these children, who cannot experience their needs such as communication and activity appropriate for their age, will likely have a slowdown in all areas of cognitive, emotional, physical and social development" (para. 12).

More support for the contributory role of the school in children's development is provided in the book entitled "Children's Health, The Nation's Wealth: Assessing and Improving Child Health" published by the National Research Council (US); Institute of Medicine (US) (2004), which states that "limitations in mobility, usual activities, or full participation in school are important aspects of physical function" (p. 36). The authors assert that "psychological function includes a wide range of functions, both cognitive (e.g., alertness, confusion, problem-solving ability, receptive language ability) and emotional (e.g., affect, mood, temperament)" (p. 36). The book further elaborates that:

Social functioning refers to limitations imposed on children in the realm of their usual activities and relationships. For a young child, the subdomains of social role function include the ability to engage in ordinary play and the ability to attend school and participate in all school-related activities. Social functioning also includes measures of social integration and social connection, including the ability to make and keep friends and to play a supportive or instrumental role in the lives of others. (National Academies Press (US), 2004, p. 36).

This reinforces the assertion that the removal of school directly impinges on the physical, psychological and social development of the child that no amount of online learning can replace. Google classroom or Zoom cannot replicate the sights, sounds and feel of actually being in school. Online learning may be suitable for adults who are doing post graduate work which is essentially an individual pursuit, but certainly for children and young adults who are still in their physical, psychosocial and emotional developmental phases, online learning can never replace the authenticity of a school or campus environment. Thus, removal of these environments is a surely a matter of grave consequences for particularly vulnerable groups of children and young adults.

\section{Conclusion and Recommendations}

It has already been made clear that enforced isolation can have massive detrimental effects on the psychosocial development and physical well-being of children. The review of the literature has proven, without a doubt, that children suffer far greater consequences as a 
https://doi.org/10.15405/ejsbs.286

eISSN: 2301-2218 / Corresponding Author: Sevim Y. Asvaroğlu

Selection \& Peer-review under responsibility of the Editors

result of the lockdown compared to adults. Adults can rationalize the lockdown and have their work or social commitments to occupy them. Children, especially the younger ones, are too immature to grasp the necessity for the enforced isolation leaving them bewildered and confused as to the reason and need for their isolation. Children have no recourse to socializing with their friends or playmates because their school environment is no longer accessible. Unlike their parents who may be able to work out in a home gym in order to keep physically fit, children pay the price of the enforced isolation as they are deprived of physical activities like playing in the park, cycling or playing games with friends. This would be especially torturous for very young children who are naturally full of energy. With no outlets to expend this energy, children would become irritable, whingy and whiny resulting in being deemed annoying by their parents, through no fault of their own. This may result in children being punished by their parents for being naughty or mischievious when in actual fact, the child is simply demonstrating his/her natural exuberance. This could be a factor for the increase in domestic abuse of children under lockdown.

Another aspect of their physical well-being may be disrupted in terms of their diet which may have degenerated to include more junk food because they are now spending more time watching TV or playing video games, leading to obesity and ill health. Their world would have shrunk to three points on a vicious circle revolving around bed, fridge and TV/gaming station or bed, dining table, TV for the little ones.

During the lockdown, their communication and interaction are limited to parents and siblings and grandparents if any. Imagine this scenario repeating itself for months. While this may not affect the very young children in the stages of infancy, early childhood and preschool, it would certainly take a heavy toll on older children who have already moved into the stages of school age and adolescence (Cherry, 2020). Children at these stages thrive on building their psychosocial competencies through interaction with peers and significant others like teachers. Hence, being thrust back into the early childhood stages would not only be regressive but also damaging in terms of their psychosocial development. This is what Bayar and Zontur (2020) talk about in terms of children in such situations experiencing "a stimulus deficit" which cause "a slowdown in all areas of cognitive, emotional, physical and social development" (para. 12). The lack of interaction has the very real danger of dampening or even deadening the natural exuberance and proactiveness of children due to the "stimulus deficit" inherent in the extended enforced isolation. The urge to socialise, experiment with interactions and learn new things from peers or age mates may be permanently damaged leaving the children unable to socialize appropriately as adults. 
Irrefutable evidence has stated that the mind-numbing routine of the lockdown would certainly scar the children both physically and psychosocially in the long run, especially those who are particularly vulnerable like children in hospitals, children displaced by war, refugee children living in internment camps, abandoned children or those whose parents or caregivers have died and left in shelters (Ghosh et al., 2020). Liu et al. (2020) assert that;

Companionship is essential for children's normal psychological development and wellbeing. Separation from caregivers pushes children into a state of crisis and might increase the risk of psychiatric disorders. Children who were isolated or quarantined during pandemic diseases were more likely to develop acute stress disorder, adjustment disorder, and grief. $30 \%$ of the children who were isolated or quarantined met the clinical criteria for post-traumatic stress disorder. Furthermore, separation from parents or parental loss during childhood also has long-term adverse effects on mental health, including a higher risk of developing mood disorders and psychosis, and death by suicide in adulthood. (p. 348)

This underscores the severity of the effects of enforced isolation on this vulnerable group of children. Their feelings of utter helplessness and abandonment, especially the very young ones, must be incomprehensible to those of us who have enjoyed a secure childhood.

However, all is not lost. Children have the gift of youth on their side which includes resilience to bounce back into their normal routine once the lockdown is lifted. As mentioned earlier, there are children who are not as badly affected by the effects of isolation as compared to others as they are able to utilise appropriate coping strategies. Children who are fortunate enough to have parents who can manage the lockdown in a productive and healthy way would be able to maintain their physical health and psychosocial development, if not optimally then at least without major damage. Caregivers in institutions or centres where children are housed must be trained to ensure that the children's needs are attended to as far as it is possible. The agency responsible for this must be held accountable for sustaining the overall well-being of the children.

For caring and concerned stakeholders, the fear is greater for those unfortunate children with dysfunctional, negligent or abusive parents or caregivers. These children have the most to fear during this lockdown. Not only do they lose out on their psychosocial development, they live in terror of when an abusive parent will lash out at them. According to Ghosh et al. (2020):

Reports of child abuse, neglect, exploitation and domestic violence are on horrendous rise at the time of COVID-19 pandemic and lockdown" where "abuse, psychological aggression and/or physical punishment by caregivers at a very early age leave 
permanent wounds in the form of impaired development of brain and psyche, higher rates of psychosomatic and neuro-psychiatric disorders, multiple substance abuse and suicidal thoughts. (p. 228)

This illustrates the insidious and long-reaching damage that can be done to the child in isolation with abusive caregivers, depriving the child of not only a happy and fulfilling childhood but also a productive adulthood. This is the group of children that the responsible government agencies and NGOs should prioritise in their identification and prevention efforts. Admittedly, one of the hardest tasks to accomplish, the identification and removal of children in such circumstances to a safer environment is of utmost importance for children are the most valuable investment that any government must protect. Damaged children will grow to become damaged adults who cannot contribute to the nation's productivity and progress. In fact, they become a burden on the nation's healthcare and, in many cases, will end up filling the nation's penitentiaries which the nation's hardworking taxpayers' contributions are used to support till the end of their unproductive lives in certain cases. Thus, early identification and removal of children at risk to safety should be considered a long-term investment by the government.

Looking at the home, some practical ways that can deter psychosocial rot in children is for parents to organise get together sessions with their children's playmates or peers living within the same premises such as the same condominium or housing area. These sessions can be hosted in different homes in turn. Such sessions can also be conducted online if face-toface meetings are prohibited. While not as authentic as the face-to-face interactions, at least the online sessions allow the children to chat with their friends which can relieve some of the psychosocial stress build up. Older children can also be encouraged to compose emails describing their feelings to their peers, while younger ones can be encouraged to draw pictures which can be scanned and sent to playmates. These can be used as conversational stimuli between the recipient children and their parents. Children can be encouraged to read books rather that watch TV or play games as reading activates the brain in terms of critical thinking, imagination and creativity. Children's brains are positively engaged with the reading material as they navigate the story and the characters dialogue and actions. Parents can then get the children to retell the story in their own words or challenge the children to provide alternative endings or alternative actions to that of the characters in the story. This will not only provide opportunities for interaction, communication and laughter, it has the added value of enhancing children's creativity, imagination, critical and predictive thinking. There is overwhelming research on the benefits of reading for pleasure for children's "social and cognitive development, their wellbeing, and their mental health" which is especially relevant in these confusing and disturbing times for children because reading "can be a 'stable source of 
information' throughout a child's life. This stability allows them to access text in a constant fashion and can be especially beneficial for children growing up in challenging circumstances" (para. 4). This has particular value at this time because reading helps children in "developing empathy", gaining deeper understanding and building stronger relationships" (Collier, 2019, para. 8) all of which can help mitigate the effects of the lockdown on children's psychosocial development.

Parents can also organise story telling or poetry reading sessions, fashion shows, dramatic sketches, cooking sessions, and handicraft making all of which can be easily learnt through the Internet for parents who are keen to ensure that their children come through the lockdown with minimal psychosocial damage. Encouraging children to participate in socialising activities can help negate the effects of enforced isolation among children (Frankenberg \& Orfield, 2007). What is important here is not the quantity of activities but the content which should be carefully selected to maximise social interaction and communication. Explaining the situation clearly and unemotionally to the children, especially the older ones, is also advisable so that children are aware of the circumstances and can help in their own way to alleviate certain stressful days for parents like taking care of their younger siblings to preparing simple meals and doing simple chores to give mom a break. This will help increase children's sense of responsibility in the home, compassion and also develop their maturity. Initiative will also be ingrained where children will take over certain household chores on their own.

Karaoke sessions would also be great fun and a great way to incorporate physical activity with some dancing while singing. Parents can motivate the children by offering small rewards for the best dance routine among the family members, grandparents included. Other ways to keep children and everyone else in the family healthy is to involve the entire family in simple yoga exercises. Yoga does not require expensive or specialised equipment. Yoga has been medically established to be an excellent exercise for every part of the body. According to the information on the Johns Hopkins Medicine (2020) webpage, "Yoga offers physical and mental health benefits for people of all ages" (para. 2) with asanas or poses specifically geared to enhance mood and energy levels which can help with fighting depression while decreasing anxiety and stress levels. Doing yoga as a family will not only strengthen the family physically but also enhance family togetherness. Block yoga classes can be organised to encourage fraternising among the children and elders, where possible.

Diet is of course of primary concern in ensuring the physical health of children. Parents and caregivers need to be aware that with more time spent at home, children without proper supervision, would naturally gravitate to watching TV or gaming. Watching TV encourages 
https://doi.org/10.15405/ejsbs.286

eISSN: 2301-2218 / Corresponding Author: Sevim Y. Asvaroğlu

Selection \& Peer-review under responsibility of the Editors

the intake of junk and fast food. Hence, the onus is on the parents and care givers to not to stock up on these items and instead stock up on health snacks or homemade snacks. Children's patterns and habits of TV watching, snacking on unhealthy foods, and not exercising are all modelled on parents' behaviours. Hence, the onus is on the parents to be good role models for healthy eating and living for the children to emulate.

Physically and cognitively, the less time the children spend on watching TV the better. Parents need to strictly enforce TV watching time and monitor the type of programmes the children are permitted to watch. Studies have established a direct link of watching too much TV and obesity among children. Even before the emergence of Covid19, in 2015, Rosiek et al. had already found that "TV viewing is a contributing factor to childhood obesity. It takes away from the time children spend on physical activities and also leads to increased energy intake through snacking and eating meals in front of the TV. Those habits of "sit time" and "snacks", and also product advertisements on TV, influence children to make unhealthy food choices" (p. 9409). One can only imagine how much the situation has been exacerbated by the lockdown. For those who may feel that childhood obesity is not a serious issue, this study has found that "obesity is the sixth most important risk factor in terms of the number of deaths in the world... the WHO officially declared obesity to be a chronic condition which requires treatment, fosters the development of other diseases, and is connected with increased mortality" (p. 9409).

All the ways recommended here would necessitate the parents and caregivers to be mindful and proactive of their family's health and well-being. It is up to the parents to take the necessary steps to ensure that their children are psychosocially and physically healthy during the lockdown. Children in institutions and shelters are legally the wards of the state and must be provided with the best care available which trained officers and NGO personnel can monitor. To reiterate John F. Kennedy, "Children are the world's most valuable resource and its best hope for the future". Losing our children to the ravages of the lockdown now or other damaging circumstances is simply not an option for any nation which cares about its future.

\section{Acknowledgements}

The author(s) declare that there is no conflict of interest. 
https://doi.org/10.15405/ejsbs.286

eISSN: 2301-2218 / Corresponding Author: Sevim Y. Asvaroğlu

Selection \& Peer-review under responsibility of the Editors

\section{References}

Bayar, G., \& Zontur, E. C. (2020, May 16). Lockdown may cause behavioural changes among children. https://www.aa.com.tr/en/latest-on-coronavirus-outbreak/lockdown-may-cause-

Cherry, K. (2020). Erik Erikson's Stages of Psychosocial Development. https://www.verywellmind. com/erik-eriksons-stages-of-psychosocial-development2795740

Collier, E. (2019). Why Reading is so Important for Children. https://www.highspeedtraining.co.uk/hub/why-is-reading-important-for-children/

Frankenberg, E., \& Orfield, G. (Eds.). (2007). Lessons in integration: Realizing the promise of racial diversity in American schools. University of Virginia Press.

Ghosh, R., Dubey, M. J., Chatterjee, S., \& Dubey, S. (2020). Impact of COVID-19 on children: Special focus on psychosocial aspect. Minerva Pediatrica, 72(3), 226-235. https://doi.org/10.23736/S0026-4946.20.05887-9

Johns Hopkins Medicine. (2020). The 9 Benefits of Yoga. https://www.hopkinsmedicine.org/health/ wellness-and-prevention/9-benefits-of-yoga

Liu, J. J., Bao, Y., Huang, X., Shi, J., \& Lu, L. (2020). Mental health considerations for children quarantined because of COVID-19. The Lancet. Child \& Adolesc Health, 4, 347-349. https://doi.org/10.1016/S2352-4642(20)30096-1

Loades, M. E., Chatburn, E., Higson-Sweeney, N., Reynolds, S., Shafran, R., Brigden, A., Linney, C., McManus, M. N., Borwick, C., \& Crawley, E. (2020). The Impact of Social Isolation and Loneliness on the Mental Health of Children and Adolescents in the Context of COVID19. J Am Acad Child Adolesc Psychiatry, 59(11), 1218-1239. https://doi.org/10.1016/j.jaac.2020.05.009

National Research Council (US); Institute of Medicine. (US). (2004). Children's Health, The Nation's Wealth: Assessing and Improving Child Health. National Academies Press (US). https://www.ncbi.nlm.nih.gov/books/NBK92198/

Orenstein, G. A., \& Lewis, L. (2020). Eriksons Stages of Psychosocial Development. In StatPearls [Internet]. StatPearls Publishing. https://www.ncbi.nlm.nih.gov/books/NBK556096/

Partridge, C. (2010). Residential schools: The intergenerational impacts on Aboriginal peoples. Native Social Work Journal, 7, 33-62. https://www.suicideinfo.ca/resource/siecno20130881/

Robison, J., Fortinsky, R., Kleppinger, A., Shugrue, N., \& Porter, M. (2009). A broader view of family caregiving: effects of caregiving and caregiver conditions on depressive symptoms, health, work, and social isolation. Journals of Gerontology Series B: Psychological Sciences and Social Sciences, 64(6), 788-798. https://doi.org/10.1093/geronb/gbp015

Rosiek, A., Maciejewska, N. F., Leksowski, K., Rosiek-Kryszewska, A., \& Leksowski, Ł. (2015). Effect of Television on Obesity and Excess of Weight and Consequences of Health. Int $J$ Environ Res Public Health, 12(8), 9408-9426. https://doi.org/10.3390/ijerph120809408

Zhang, X., Zhu, W., Kang, S., Qiu, L., Lu, Z., \& Sun, Y. (2020). Association between physical activity and mood states of children and adolescents in social isolation during the CoViD19 epidemic. International journal of environmental research and public health, 17(20), 7666. https://doi.org/10.3390/ijerph17207666 